Laranja, D.H.R. Observação de aves: uma ferramenta de Educação Ambiental no Parque Estadual Cantareira. Anais do VIII Congresso Nacional de Ecoturismo e do IV Encontro Interdisciplinar de Ecoturismo em Unidades de Conservação. Revista Brasileira de Ecoturismo, São Paulo, v.4, n.4, 2011 , p. 552.

\title{
OBSERVAÇÃO DE AVES: UMA FERRAMENTA DE EDUCAÇÃO AMBIENTAL NO PARQUE ESTADUAL CANTAREIRA
}

\section{Diego Hernandes Rodrigues Laranja*}

*Universidade Federal de São Carlos - Câmpus Sorocaba/Fundação Florestal (SP)

\author{
E-mail: diegohrl@yahoo.com.br
}

Unidades de Conservação inseridas na região metropolitana de São Paulo vem se tornando importantes equipamentos de lazer e educação ambiental para a sociedade, pois se configuram atualmente como locais nos quais as pessoas se sentem descansadas e livres das obrigações cotidianas, estando assim abertas para uma reflexão sobre as condições ambientais que todo o desenvolvimento e o modo de vida do ser humano moderno trouxeram como marcas do século XX. O artigo trata da atividade de observação de aves e das possibilidades deste segmento do ecoturismo como forma de promover a educação ambiental para pessoas de todas as idades que visitam o Parque Estadual da Cantareira (PEC). Através de três aulas experimentais com escolas visitantes do PEC foi aplicada uma atividade antes e após a visita, com o intuito de identificar conceitos que os alunos carregam sobre meio ambiente, mata atlântica, biodiversidade de aves e tráfico de animais silvestres. Foi feito o censo da comunidade de aves e dos locais de maior possibilidade de avistamento dentro e no entorno da UC, além da comparação com dados da Avaliação Ecológica Rápida (AER) realizada para a comunidade de aves durante a revisão de Plano de Manejo. Os resultados mostram que a UC possui grande importância ecológica e potencial para a realização da atividade de observação de aves, podendo ser utilizada no desenvolvimento do ecoturismo e de atividades educativas para as escolas do entorno da unidade. Destaca a possibilidade de acréscimo qualitativo no processo de ensino aprendizagem de ciências e biologia no tratamento de temas interdisciplinares como a modificação da paisagem natural abordados durante aulas de campo, tendo a UC como ambiente não-formal de ensino.

Palavras-chave: Avifauna; Ecoturismo; Áreas de Conservação. 